\title{
EDITORIAL
}

\section{O DESAFIO DA EDITORAÇÃO DE UMA REVISTA CIENTÍFICA}

\author{
Olga Maimoni Aguillar
}

Marcia Bucchi Alencastre

Após três anos na coordenação da Comissão de Editoração da Revista Latino-Americana de Enfermagem, temos a sensação de que ainda há tanto a fazer e tanto a aprender sobre editoração científica, apesar do muito que caminhamos.

Ao assumirmos essa responsabilidade em 1992, tínhamos conhecimento dos aspectos formais e gerenciais relativos à editoração, adquiridos através de participação em encontros de editores, leituras de bibliografias pertinentes, consultas a editores científicos de revistas tradicionais, visitas e estágios em outros órgãos editoriais. Entretanto, não fazíamos idéia da complexidade e diversidade dos imprevistos que nos aguardavam a cada momento do transcorrer desse processo. Desde a obtenção de subsídios à composição do Conselho Editorial, divulgação do periódico, administração orçamentária, formação de recursos humanos de apoio até a dinâmica propriamente dita da editoração e publicação.

Em uma área emergente em pesquisa como a enfermagem, a composição de um Conselho Editorial mostrou-se um processo complicado. Pela abrangência que se propõe uma revista latino-americana, a representatividade em termos de regiões e países foi considerada. Como é do nosso conhecimento, são poucos os cursos de doutoramento em enfermagem no Brasil e América Latina, fato este que limita a disponibilidade de profissionais com formação para atuarem como consultores. Essa limitação foi sentida por nós com maior intensidade quando organizamos o Conselho segundo área de conhecimento, a especificidade das temáticas contribuiu para a pulverização dos recursos humanos, já escassos.

Tão importante quanto a composição é a habilidade dos profissionais para exercer a atividade de relator de trabalhos científicos. Nesse aspecto é interessante salientar que, se por um lado os autores de trabalhos enviados para publicação, jovens pesquisadores em sua grande maioria, nem sempre estão habituados a receber 
críticas e sugestões sobre sua produção, por outro lado os relatores, cônscios de sua responsabilidade são extremamente exigentes em seus pareceres, criando muitas vezes situações de impasse para a Comissão de Editoração, que tem se pautado pela não recusa sumária de trabalhos, mas sim pelo máximo aproveitamento do potencial dos pesquisadores.

Sentidos hoje que grande parte das dificuldades iniciais, inerentes à editoração de um periódico científico, foram superadas em função de um trabalho criterioso, realizado com compromisso e motivação. Entretanto, sabemos também que dois grandes desafios estão pela frente. Um representado pela busca de novos subsídios que assegurem as futuras publicações e outro pela necessidade de conscientização dos enfermeiros, sobre a importância de sua participação para a continuidade deste projeto, no âmbito da América Latina. 


\section{EDITORIAL}

\section{EL DESAFÍO DE LA EDICIÓN DE UNA REVISTA CIENTÍFICA}

Olga Maimoni Aguillar

Marcia Bucchi Alencastre

Después de tres años en la coordinación de la Comisión de Edición de la Revista Latinoamericana de Enfermería, tenemos de que aún hay tanto para hacer y tanto para aprender sobre edición científica, a pensar de lo mucho que caminamos.

Al asumir nosotros esa responsabilidad en 1992, teníamos conocimiento de los aspectos formales y gerenciales relativos a la edición, adquiridos a través de la participación en encuentros de editores, lecturas de bibliografías pertinentes, consultas a editores científicos de revistas tradicionales, visitas y pasantías en otros órganos editoriales. Entretanto, no hicimos la idea de la complejidad y diversidad de los imprevistos que nos esperaban a cada momento al transcurrir de ese proceso; desde la obtención de subsidios hasta la composición del ensejo editorial, divulgación de la revista, administración del presupuesto, formación de recursos humanos de apoyo, y la dinámica propiamente dicha de edición y publicación.

En una área emergente en investigación, como lo es enfermería, la composición de un consejo editorial se convirtió en un proceso complicado, por la cobertura que se propone la revista latinoamericana y la representatividad en términos de regiones y países, fue considerable. Como es de nuestro conocimiento, son pocos los cursos de doctorado en el Brasil y en América Latina, hecho este que limita la disponibilidad de profesionales con formación, para que actúen como consultores. Esa limitación fue sentida por nosotros con mayor intensidad, cuando organizamos el consejo, según áreas de conocimiento, la especificidad de las temáticas contribuyó para la dilución de los recursos humanos, de por sí escasos.

Tan importante como la composición, es la habilidad de los profesionales para ejercer la actividad de relator de los trabajos científicos. En ese aspecto es interesante resaltar que, por un lado los autores de trabajos enviados para publicación, 
Son jóvenes investigadores en su mayoría, no siempre están acostumbrados a recibir críticas y sugerencias sobre su producción, por otro lado los relatores, conscientes de su responsabilidad son extremamente exigentes en sus opiniones, creando muchas veces, impares para la Comisión de Edición, que tiene como pauta, el no rechazo sumario de los trabajos, más si el máximo aprovechamiento del potencial de los investigadores.

Sentimos hoy, que gran parte de las dificultades iniciales, inherente a la edición de una revista científica fueran superadas en función de un trabajo juicioso, esperan dos grandes desafíos, uno representado en la búsqueda de nuevos subsidios que aseguren las nuevas publicaciones y otro por la necesidad de conscientización de los enfermeros, sobre la importancia de su participación para la continuidad de este proyecto, en ámbito de América Latina. 